\title{
Utilising thermal annealing for multiplexing and sensitivity enhancement of polymer optical fibre sensors
}

Pospori, A.; Marques, C. A.F.; Sagias, G.; Lamela-Rivera, H.; Sáez-Rodríguezd, D.; Nielsen, K.; Bang, O.; Webb, D. J.

\section{Published in:}

Proceedings of SPIE

Link to article, DOI:

$10.1117 / 12.2541767$

Publication date:

2019

Document Version

Publisher's PDF, also known as Version of record

Link back to DTU Orbit

Citation (APA):

Pospori, A., Marques, C. A. F., Sagias, G., Lamela-Rivera, H., Sáez-Rodríguezd, D., Nielsen, K., Bang, O., \& Webb, D. J. (2019). Utilising thermal annealing for multiplexing and sensitivity enhancement of polymer optical fibre sensors. In K. Kalli, G. Brambilla, \& S. O'Keeffe (Eds.), Proceedings of SPIE (Vol. 11199). [111993E] SPIE - International Society for Optical Engineering. Proceedings of SPIE - The International Society for Optical Engineering Vol. 11199 https://doi.org/10.1117/12.2541767

\section{General rights}

Copyright and moral rights for the publications made accessible in the public portal are retained by the authors and/or other copyright owners and it is a condition of accessing publications that users recognise and abide by the legal requirements associated with these rights.

- Users may download and print one copy of any publication from the public portal for the purpose of private study or research.

- You may not further distribute the material or use it for any profit-making activity or commercial gain

- You may freely distribute the URL identifying the publication in the public portal 


\title{
Utilising thermal annealing for multiplexing and sensitivity enhancement of polymer optical fibre sensors
}

\begin{abstract}
A. Pospori, C. A. F. Marques, G. Sagias, H. LamelaRivera, D. Sáez-Rodríguezd, et al.
\end{abstract}

A. Pospori, C. A. F. Marques, G. Sagias, H. Lamela-Rivera, D. SáezRodríguezd, K. Nielsen, O. Bang, D. J. Webb, "Utilising thermal annealing for multiplexing and sensitivity enhancement of polymer optical fibre sensors," Proc. SPIE 11199, Seventh European Workshop on Optical Fibre Sensors, 111993E (28 August 2019); doi: 10.1117/12.2541767

Event: Seventh European Workshop on Optical Fibre Sensors, 2019, Limassol, Cyprus 


\title{
Utilising thermal annealing for multiplexing and sensitivity enhancement of polymer optical fibre sensors
}

\author{
A. Pospori*a, C. A. F. Marques ${ }^{b}$, G. Sagias ${ }^{\mathrm{c}}$, H. Lamela-Rivera ${ }^{\mathrm{c}}$, D. Sáez-Rodríguez ${ }^{\mathrm{d}}$, K. Nielsen ${ }^{\mathrm{e}}$, \\ O. Bang ${ }^{\text {e }}$ D. J. Webb ${ }^{\mathrm{d}}$ \\ aPhotonics and Optical Sensors Research Laboratory, Cyprus University of Technology, \\ Saripolou 33, 3036, Limassol, Cyprus \\ ${ }^{b}$ University of Aveiro, Physics Department \& I3N, Campus de Santiago, 3810-193 Aveiro, Portugal \\ 'Opto-Electronics and Laser Technology Group, Universidad Carlos III de Madrid, Edificio Sabatini, \\ Leganés Madrid, 28911, Spain \\ ${ }^{\mathrm{d}}$ Aston Institute of Photonic Technologies, Aston University, Aston Triangle, Birmingham, B7 4ET, \\ United Kingdom \\ eDTU Fotonik, Department of Photonics Engineering, DK-2800 Kgs. Lyngby, Denmark \\ *andreas.pospori@cut.ac.cy; orcid.org/0000-0003-4866-1361
}

\begin{abstract}
Thermal annealing was initially introduced for multiplexing purposes, since it can induce a permanent negative Bragg wavelength shift for polymer fibre grating sensors. At a later stage, it is shown that annealing can also provide additional benefits, such as strain and humidity sensitivity enhancement and augmented temperature operational range. In this paper, we report additional usage of thermal annealing on PMMA fibre Bragg grating sensors. We show the possibility to tune Bragg wavelengths to longer wavelengths permanently by stretching the polymer optical fibre during the thermal annealing process. An array of sensors fabricated with only one phase-mask, demonstrates the concept by having Bragg wavelengths below and above the original inscribed spectral position. In addition, we report that thermal annealing can be also used to enhance the performance of sensors when used for stress and force monitoring.
\end{abstract}

Keywords: Polymer optical fibre, Bragg gratings, annealing, multiplexing, stress sensitivity, force sensitivity

\section{INTRODUCTION}

Polymer optical fibres (POFs) have higher flexibility in bending, higher fracture toughness and higher failure strain compared with their silica counterparts ${ }^{1}$. The lower Young modulus of polymers renders POF Bragg grating (POFBG) sensors to have enhanced sensitivity when used in stress ${ }^{2}$ and pressure $^{3}$ monitoring applications. The large thermo-optic coefficient of most polymers can also provide higher temperature sensitivity compared with the silica-based Bragg grating sensors ${ }^{4}$. Furthermore, some polymers are hydrophilic; therefore, POFBGs can be effectively used for humidity measurements ${ }^{5}$. Besides the advantages, the POF technology is not mature enough yet; it has some drawbacks, such as high optical attenuation and complicated photosensitivity mechanisms involved during POFBG inscription procedures ${ }^{1}$. In addition, the anisotropic structure of the drawn fibre to a degree that depends on the magnitude of the fibre drawing stress and the visco-elastic nature of polymers that causes hysteresis and creep effects when POF is under mechanical cycling loading can be also considered as disadvantages ${ }^{1}$.

POF thermal annealing was utilised to reduce hysteresis effects ${ }^{6}$, enhance humidity ${ }^{7}$ and strain $^{8}$ sensitivity, increased temperature monitoring operational range ${ }^{9}$, recover and increase the reflectivity of POFBGs ${ }^{10}$. The annealing process was first introduced for POFBG multiplexing purposes ${ }^{11}$, using only one phase-mask to record multiple Bragg gratings. Due to the tendency of the anisotropically drawn polymer fibre to physically shrink in length when heated above the $\beta$-transition temperature, thermal annealing can be used to shift Bragg wavelengths to shorter wavelengths permanently. The rate of fibre shrinkage depends on the annealing conditions (duration, temperature and humidity), chemical composition of polymer material, and thermal processing history, including the POF drawing conditions ${ }^{12}$. Climatic-controlled chambers are usually used to anneal the POFs with pre-defined annealing conditions (temperature and humidity) and the process takes between few hours and several days ${ }^{9,11}$. Recently, a simpler and cost-effective

Seventh European Workshop on Optical Fibre Sensors, edited by Kyriacos Kalli, Gilberto Brambilla, Sinead O'Keeffe Proc. of SPIE Vol. 11199, 111993E · C 2019 SPIE · CCC code: 0277-786X/19/\$21 - doi: 10.1117/12.2541767 
annealing method was demonstrated, in which the POFs were annealed in heated water (100\% humidity) for few seconds up to few minutes ${ }^{13}$.

\section{MULTIPLEXING}

In all reported annealing experiments, the POFs were loose without any external force being applied on them during the thermal annealing process. Without applying any external force during the annealing process, the POFBGs shrink in length and the Bragg wavelength permanently shift to shorter wavelengths. Thus, the multiplexing of sensors is feasible only at wavelengths below the original spectral position of Bragg grating. The permanent shifting can be an issue in cases where annealing is used for purposes other than multiplexing and the Bragg wavelength is desired to be kept at its original spectral position. There is no method reported until now to permanently tune the Bragg wavelength to longer wavelengths. In this paper, we report a novel annealing method, which utilizes the fibre axial strain during the annealing process to tune the Bragg wavelength at any desirable spectral position over a spectral range that extends above the recorded Bragg wavelength. The same experiments were performed by two different research groups to prove the concept; the POFBGs were placed in heated water for annealing and the POFs were kept stretched during the process. The POFBG were fabricated with the phase-mask technique using a 325-nm He-Cd (Kimmon IK3301R-G) and 248-nm $\mathrm{KrF}$ (Coherent Bragg Star Industrial-LN) in a single-mode PMMA microstructured fibre, having a core doped with benzyl-dimethyl-ketal for photosensitivity enhancement ${ }^{14}$. The diameter of POF is $130 \mu \mathrm{m}$ and the core size is $8 \mu \mathrm{m}$. The $\beta$-transition temperature of PMMA is approximately at $50 \pm 5{ }^{\circ} \mathrm{C}$ and above that temperature, the molecules start to become mobilised ${ }^{15}$. The POF was placed in a tank filled with water which was heated up to $80^{\circ} \mathrm{C}$. The fibre was strained using a translation stage. More details about the annealing methodology and the experimental setup can be found in reference ${ }^{16}$.

Figure 1(a) shows the red shifting of 2 POFBG performed by research group 1 and group 2 . Results show that the new Bragg wavelength spectral position depends on the applied fibre strain and that fibre stretching is an important parameter to consider during the annealing process, since it determines the direction and degree of Bragg wavelength shifting. Figure 1(b) depicts an array of 5 POFBGs along the same fibre piece. The 5 POFBGs were inscribed with the same phase-mask (period of $568 \mathrm{~nm}$ ) and the Bragg wavelength was centred at $844.2 \mathrm{~nm}$. Each POFBG was annealed with a different strain percentage: the first POFBG was annealed without applying any fibre strain and it was tuned from $844.2 \mathrm{~nm}$ to $837.0 \mathrm{~nm}$. The second POFBG was not annealed, so it remained at its original spectral position $(844.1 \mathrm{~nm})$. The third, fourth, and fifth POFBG were annealed with $0.65 \%, 1.3 \%$ and $2.3 \%$ strain, respectively. Therefore, their Bragg wavelengths were tuned from $844.2 \mathrm{~nm}$ to $847.7 \mathrm{~nm}, 854.9 \mathrm{~nm}$, and $866.5 \mathrm{~nm}$, respectively. In conclusion, Figure 1(b) demonstrates the ability to tune the Bragg wavelengths to any desirable spectral position (negative or positive wavelength tuning) by appropriately selecting the degree of fibre strain during the annealing process.
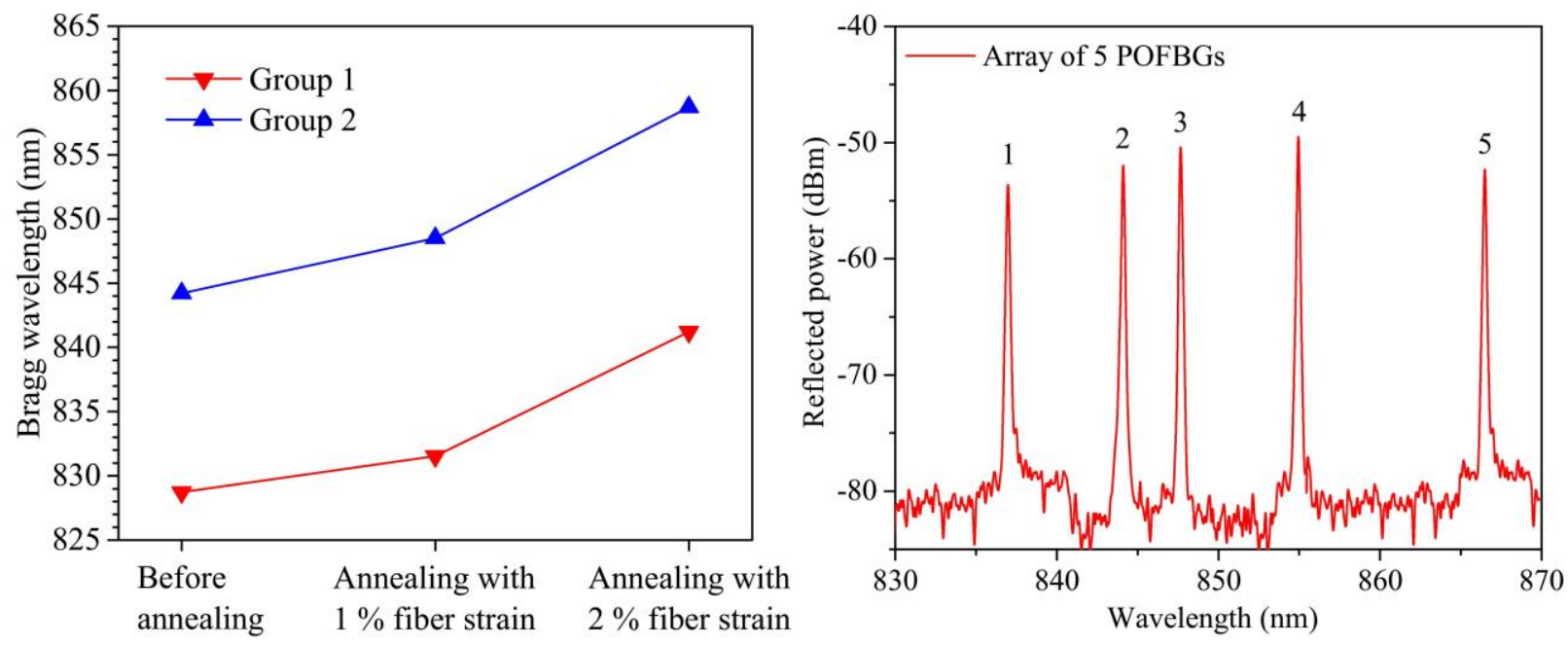

Figure 1: (a) Bragg wavelength shift before and after annealing with $1 \%$ and $2 \%$ strain, (b) Array of 5 POFBGs 


\section{STRESS AND FORCE SENSITIVITY ENHANCEMENT}

A thermal annealing has been applied to POF Bragg grating sensors in order to investigate their influence on stress and force sensitivity. First, the Bragg grating sensors were photo-inscribed in a single-mode PMMA optical fibre ${ }^{14}$ using the phase-mask technique. Then, each sensor was characterised with respect to its strain, stress, and force sensitivity, as described in reference ${ }^{13}$. After POFs were thermally annealed in a container filled with hot water. More details about the annealing methodology can be found in reference ${ }^{13}$. After the annealing, the sensitivities of the POFBG sensors were characterised again and were compared with the pre-annealing sensitivities. Results show that the thermal annealing can enhance not only the strain sensitivity of POF Bragg grating sensors as already reported in the literature ${ }^{8}$, but also the stress and force sensitivities, as depicted in Figure 2(a) and Figure 2(b), respectively.
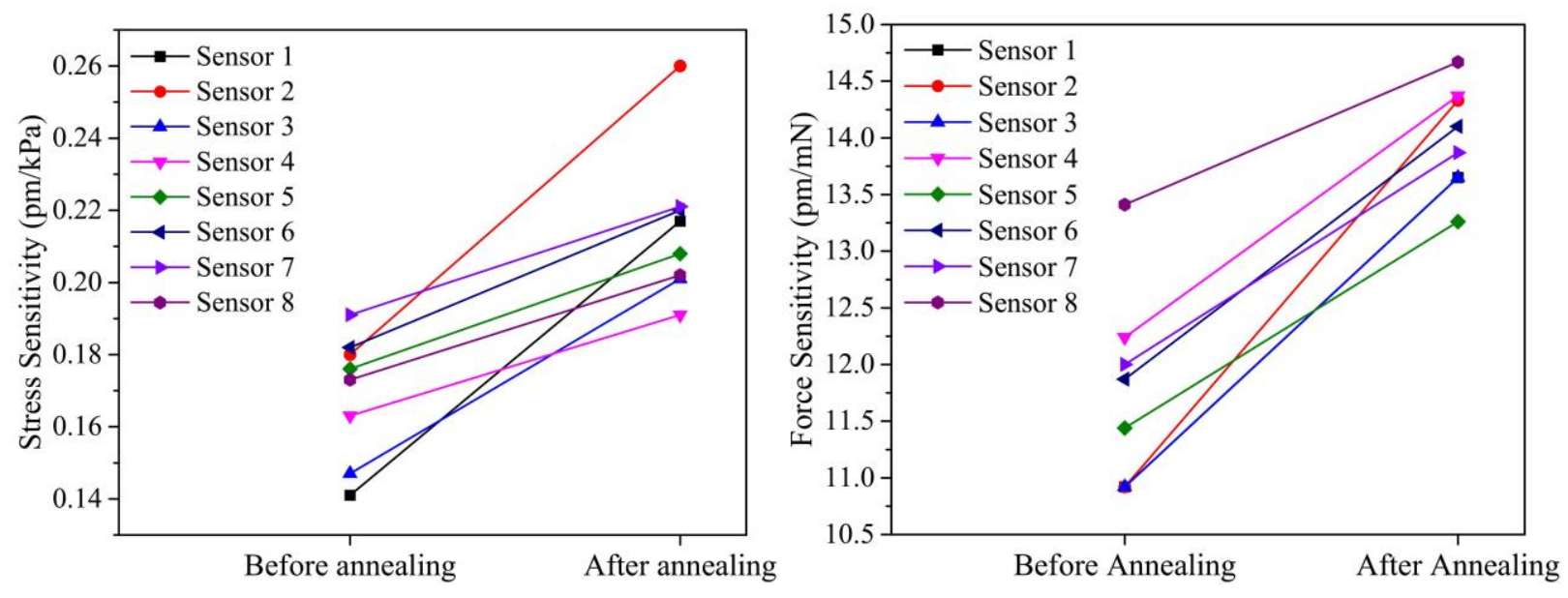

Figure 2: (a) Stress sensitivity before and after annealing, (b) Force sensitivity before and after annealing

The explanation for the stress and force sensitivity enhancement is the following. During the drawing process, highly oriented polymer sections are produced ${ }^{17}$ and the stretched elastomers that have cooled down have less mobile chains than in the bulk material. Heating the polymer above the $\beta$-transition temperature in the absence of any external force acting on the polymer material allows each molecule chain to relax towards its equilibrium state, becoming highly amorphous again by reorganizing its conformation ${ }^{18}$. This molecular rearrangement removes the residual internal stress and as a result the elasticity of the material increases, which leads to sensitivity enhancement for the fibre-based sensors.

\section{CONCLUSION}

Thermal annealing can be utilised for multiplexing purposes as proposed in this paper. Controlling the fibre strain during the annealing process is an important parameter to consider when tuning Bragg wavelengths to shorter or longer wavelengths. Note that the annealing methodology presented in this paper cannot be applied in cases where the POFBGs are very close to each other physically. It would require a very confined heated region in order to not affect the adjacent grating structure. Note also that stretching the POFBG for tuning to longer wavelengths could possibly lead to higher internal stress. Therefore, the effects of the proposed annealing methodology on mechanical properties of POF should be investigated in future experiments. On the other hand, thermal annealing can be used to increase stress and force sensitivity according the application requirements, if the POFBGs are annealed without any applied fibre stress. The reason for the sensitivity enhancement is probably due to the molecular relaxation of the material, when the POF is exposed above the $\beta$-transition temperature. It is clear that a proper thermal annealing regime should be established before sensors are used in applications requiring optimised, long term, stable operation. 


\section{ACKNOWLEDGMENT}

The research leading to these results has received funding from the People Programme (Marie Curie Actions) of the European Union's Seventh Framework Programme FP7/2007-2013/ under REA grant agreement No. 608382. This work was supported by Marie Curie Intra European Fellowships included in the 7th Framework Program of the European Union (projects PIEF-GA-2013-628604 and PIEF-GA-2011-302919). Funding has been also received from the Horizon 2020 programme of European Union (Marie Skłodowska-Curie Actions - Individual Fellowships) under REA grant agreement No. 844618 (project POSPORI).

\section{REFERENCES}

[1] J. W. David, "Fibre Bragg grating sensors in polymer optical fibres," Measurement Science and Technology, 26(9), 092004 (2015).

[2] T. X. Wang, Y. H. Luo, G. D. Peng, Q. J. Zhang, "High-sensitivity stress sensor based on Bragg grating in BDK-doped photosensitive polymer optical fiber", Proc. SPIE 8351, 83510M (2012).

[3] C. A. F. Marques, A. Pospori, D. Saez-Rodriguez, et al., "Aviation Fuel Gauging Sensor Utilizing Multiple Diaphragm Sensors Incorporating Polymer Optical Fiber Bragg Gratings", IEEE Sensors J. 16(15), 6122-6129 (2016).

[4] Z. Zhang, P. Zhao, P. Lin, and F. Sun, "Thermo-optic coefficients of polymers for optical waveguide applications," Polym. J. 47, 4893-4896 (2006).

[5] W. Zhang, D. J. Webb, and G. D. Peng, "Investigation Into Time Response of Polymer Fiber Bragg Grating Based Humidity Sensors," J. Lightwave Technol. 30, 1090-1096 (2012).

[6] A. Abang, and D. J. Webb, "Effects of annealing, pre-tension and mounting on the hysteresis of polymer strain sensors, " Meas. Sci. Technol, 25(1), 015102 (2014).

[7] G. Woyessa, K. Nielsen, A. Stefani, et al., "Temperature insensitive hysteresis free highly sensitive polymer optical fiber Bragg grating humidity sensor," Opt. Express, 24(2), 1206-1213 (2016).

[8] W. Yuan, A. Stefani, M. Bache, et al., "Improved thermal and strain performance of annealed polymer optical fiber Bragg gratings," Opt. Comm., 284, 176-182 (2011).

[9] K. E. Carroll, C. Zhang, D. J. Webb, et al., "Thermal response of Bragg gratings in PMMA microstructured optical fibers", Opt. Express 15(14), 8844-8850 (2007).

[10] X. Hu, D. Kinet, P. Mégret, and C. Caucheteur, "Control over photo-inscription and thermal annealing to obtain high-quality Bragg gratings in doped PMMA optical fibers," Opt. Lett., 41(13), 2930-2933 (2016).

[11] I. P. Johnson, D. J. Webb, and K. Kalli, "Utilisation of thermal annealing to record multiplexed FBG sensors in multimode microstructured polymer optical fiber," Proc. SPIE 7753, 77536T (2011).

[12] J.J. Tribone, J.M. O’Reilly, and J. Greener, "Analysis of enthalpy relaxation in poly (methyl methacrylate): effects of tacticity, deuteration, and thermal history," Macromolecules 19(6), 1732-1739 (1986).

[13] A. Pospori, C. A. F. Marques, D. Sáez-Rodríguez, et al., "Thermal and chemical treatment of polymer optical fiber Bragg grating sensors for enhanced mechanical sensitivity," Opt. Fiber Technol. 36(7), 68-74 (2017).

[14] D. Sáez-Rodríguez, K. Nielsen, H.K. Rasmussen, et al., "Highly photosensitive polymethyl methacrylate microstructured polymer optical fiber with doped core," Opt. Lett. 38(19), 3769-3772 (2013).

[15] K. Fukao, S. Uno, Y. Miyamoto, et al., "Dynamics of $\alpha$ and $\beta$ processes in thin polymer films: Poly(vinyl acetate) and poly(methyl methacrylate)," Phys. Rev. E 64(5), 051807 (2001).

[16] A. Pospori, C. A. F. Marques, G. Sagias, et al., "Novel thermal annealing methodology for permanent tuning polymer optical fiber Bragg gratings to longer wavelengths," Opt. Express 26, 1411-1421 (2018).

[17] S. Fakirov, [Oriented polymer materials] Wiley Online Library, (1996).

[18] E. Muzeau, J. Perez, G. P. Johari, "Mechanical Spectrometry of the Beta-Relaxation in Poly(Methyl Methacrylate)", Macromolecules 24(16), 4713-4723 (1991). 